\title{
Predicting and reducing risk of exacerbations in children with asthma in the primary care setting: current perspectives
}

This article was published in the following Dove Press journal:

Pragmatic and Observational Research

19 August 2016

Number of times this article has been viewed

\author{
Steve Turner \\ Child Health, Royal Aberdeen \\ Children's Hospital, University of \\ Aberdeen, Aberdeen, UK
}

Correspondence: Steve Turner Child Health, Royal Aberdeen Children's Hospital, University of Aberdeen, Aberdeen, AB25 2ZG, UK

Tel +44 I 224438470

Email s.w.turner@abdn.ac.uk.

\begin{abstract}
Childhood asthma is a very common condition in western countries and is becoming more prevalent worldwide. Asthma attacks (or exacerbations) affect the quality of life for child and parent, can rarely result in death, and also come at a cost for health care providers and the economy. The aims of this review were to 1) describe the burden of asthma exacerbations, 2) describe factors that might predict a child at increased risk of having an asthma attack, and 3) explore what interventions might be delivered in primary care to reduce the risk of a child having an asthma attack. Asthma attacks are more common in younger children and those with more severe asthma, although prevalence varies between countries. Many factors are associated with asthma attacks including environmental exposures, patient-clinician relationship, and patient factors. Currently, the best predictor of an asthma attack is a history of an attack in the previous 12 months, and the more attacks, the greater the risk. Looking ahead, it is likely that surveillance of routinely collected primary care data can be used to identify an individual at increased risk. Stratified (or personalized) treatment, which might involve physiological monitoring and genetic analysis, offers the potential to reduce an individual's risk of asthma attack. Whatever the future holds, the relationship between patient and clinician will remain central to asthma management.
\end{abstract}

Keywords: asthma, child, prednisolone, primary prevention, recurrence

\section{Introduction}

Asthma is an enigmatic condition, where there is no universally accepted definition or diagnostic test but is commonly diagnosed and treated in primary care. The World Health Organization estimates that there are 235 million people with asthma and that asthma is the most common chronic childhood condition. ${ }^{1}$ Childhood asthma is common in all western countries and is becoming more prevalent in Central and South America, Eastern Europe, and Africa. ${ }^{2}$ Asthma symptoms characteristically follow a remitting-relapsing course. Although many children apparently "grow out of" their asthma symptoms, symptoms can recur in early adulthood, ${ }^{3}$ and childhood asthma is now recognized to be a risk factor for chronic obstructive pulmonary diseases. ${ }^{4}$

From the patient's perspective, asthma control and asthma attacks (or exacerbations) are the two aspects of asthma that impact the quality of life. In adults, current control is a good predictor of future exacerbations, and absence of attack in 12 months is part of the Global initiative for Asthma's definition of controlled asthma. ${ }^{5}$ The relationship between control and attack is not so clear in children where control is often very good for the majority of time ${ }^{6}$ but there are episodes of exacerbation, usually associated with rhinovirus infection. 
Asthma control can be defined as "the extent to which the manifestations of asthma can be observed in the patient, or have been reduced or removed by treatment" ${ }^{\text {"7 }}$ and is measured using validated questionnaire such as the Children's Asthma Control Test. ${ }^{8}$ Severe asthma attacks are defined as "events that require urgent action on the part of the patient and physician to prevent a serious outcome, such as hospitalization or death from asthma", and moderate asthma exacerbations are "events that are troublesome to the patient, and that prompt a need for a change in treatment, but that are not severe. These events are clinically identified by being outside the patient's usual range of day-to-day asthma variation". ${ }^{7}$ The treatmentbased definitions of severe and moderate attacks do have some subjectivity in terms of cutoff values for respiratory rare, heart rate, and oxygen saturations, but the definition of an attack is mostly subjective and determined by a physician's decision to start a course of oral corticosteroids (OCS). There is no agreed definition of a mild exacerbation due to blurring with poor asthma control, although in a child with mostly well-controlled symptoms a minor exacerbation is perhaps more easily identified and particularly in association with an upper respiratory tract infection.

The focus of this review is asthma attacks in children; having defined an asthma attack, this review will now include three sections that 1) describe the burden of asthma attacks, 2) describe factors linked to the risk of asthma attack in children, and 3) explore what interventions might be delivered in primary care to reduce the risk of a child having an asthma attack

\section{The burden of asthma attacks in children}

The burden of asthma per se in children is well described, but the burden of asthma attacks is not so well known. The prevalence of asthma attacks depends on the definition used. A large database study of primary care records in the UK found that $\sim 20 \%$ of children aged $<5$ years with an asthma diagnosis and treated with inhaled corticosteroids received at least one course of OCS annually and this proportion was $12 \%$ in children aged 5-11 years. ${ }^{9}$ Among 5- to 12-year olds whose asthma treatment was stepped up from inhaled corticosteroid treatment, $20 \%$ had received OCS in the previous year. ${ }^{10}$ Primary care data from the Netherlands report an incidence of severe attacks (ie, OCS or attendance at emergency department [ED] or admission to hospital) of 4 per 100 person-years, ${ }^{11}$ a figure that is considerably lower than that the UK studies of children treated with inhaled corticosteroids. ${ }^{9}{ }^{10} \mathrm{~A}$ study of French children aged 6 months to 2 years treated with inhaled corticosteroids or leukotriene receptor antagonists reports that over 6 months, $61 \%$ and $49 \%$ were prescribed oral prednisolone, respectively. ${ }^{12}$ The European Respiratory Society's White Book ${ }^{13}$ presents the prevalence of hospital admission for under 15-year olds per 100,000 head of population for 27 countries (data were not available in 23 countries); the median prevalence was 196/100,000 and the lowest was in Iceland $(38 / 100,000)$ and the highest in Latvia $(507 / 100,000)$. A further study that used data from children with asthma from five studies across the UK, the Netherlands, and the US reported attacks in $10 \%$ recruited from primary care, $44 \%-47 \%$ where recruitment was from primary and secondary care, and $75 \%$ where recruitment was only from secondary care. ${ }^{14}$ In the US, $40 \%$ of children with asthma required urgent care visits for asthma and this proportion was equal across all ethnic groups although when ED visits specifically were analyzed, $38 \%$ of Black children and $15 \%$ of White children had a recent ED visit. ${ }^{15}$ Together, these international data demonstrate that asthma attacks are common in children living in western countries but that the prevalence differs between countries. The heterogeneity in asthma attack prevalence probably reflects the different definitions of asthma attack used, the age and asthma severity of the population studied, and factors specific to the health care system in individual countries.

Hospital admission data can give insight to the prevalence of more severe asthma attacks. In England, the annual population prevalence of hospital admission with asthma was 2.8/1,000 in 2000 and this proportion was unchanged at 2.6/1,000 in 2013 (Figure 1). This prevalence is roughly comparable with data from Scotland, which show a rate of 2.1 admissions per 1,000 children in the population in 2000 and 2.0/1,000 in 2013 (Figure 1). Although the overall incidence of childhood asthma may be falling, ${ }^{16}$ the burden of severe asthma attacks remains constant. When more lifethreatening hospital admissions (coded "status asthmatics") are examined (Figure 1), there is evidence of a reduction in numbers and this might reflect diagnostic reflagging (status asthmaticus is an old diagnosis) or a reduction in the most severe presentations of asthma attacks over time.

Childhood asthma attacks present a burden to the child in terms of quality of life and also a burden to the society in terms of lost education, parental absence from work, and direct cost to health care services. It can be difficult to tease out the burden due to attacks from asthma as a whole but there are studies that have given some insight. In a study, 388 children examined and discharged from the ED with an acute asthma attack were followed up by telephone 2 weeks after having presented; $45 \%$ had missed more than 2 days of school, while $54 \%$ of parents had missed at least 1 day 


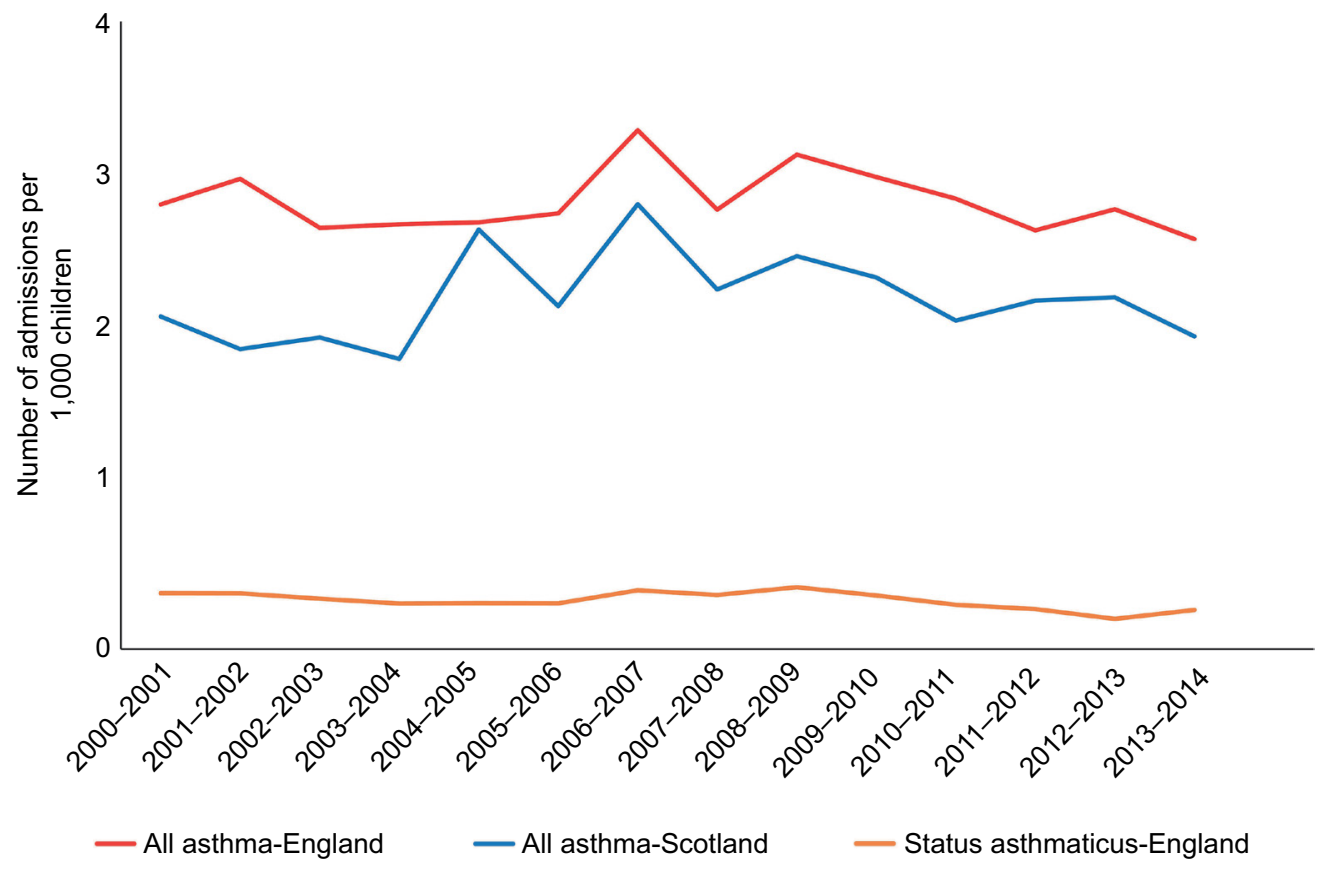

Figure I The prevalence of asthma admissions in the pediatric populations of England (red line) and Scotland (blue line) between 2000 and 2014. Notes: Data for England were obtained from Hospital Episode Statistics, ${ }^{47}$ and data for Scotland were provided by the Information Services Division of the Scottish Government to Dr Turner in 20I5. The orange line denotes the prevalence of admission in England with severe asthma (coded as "Status asthmaticus").

of work. ${ }^{17}$ Thirteen percent had to revisit the ED within 2 weeks. ${ }^{17}$ Asthma deaths are tragic but fortunately very uncommon in children, for example, 28 of the 193 deaths investigated in the National Review of Asthma Deaths (NRAD) occurred in the those less than 18 years old. ${ }^{18}$

The management of asthma costs the National Health Service $£ 1$ billion per annum, and on a pro rata basis $\sim £ 200$ million is spend on caring for children with asthma and at least one-third of the UK national health care costs attributable to childhood asthma are due to urgent care, ${ }^{19,20}$ put in another way, the UK spends $\sim £ 180,000$ each day caring for children with asthma attacks. A systematic review described the economic burden of asthma in all ages, and after considering 68 papers from western countries, the authors concluded that the cost varied by the patient's age and the severity of their disease, that costs differed between countries, and that the majority of direct health care costs were due to hospitalization..$^{21}$ This systematic review was published in 2009 when costs were rising, and it is reasonable to assume that this rise has continued.

\section{Factors associated with childhood asthma attacks}

As described in the previous section, asthma attacks are more common in younger children and with more severe asthma (as evidenced by treatment step) (Table 1). Asthma is traditionally considered to be an allergic condition, but between $38 \%$ and $80 \%$ of attacks are associated with rhinovirus infection ${ }^{22,23}$ and the evidence for allergen exposure causing asthma attacks is very limited. ${ }^{24}$ Rhinovirus infection is at least partly responsible for the well-described September "asthma epidemic", which is as predictable as the pre-Christmas bronchiolitis epidemic, and in North America occurs in the calendar week 38, ie, 4 weeks after the schools reopen after the summer holidays. ${ }^{25}$ The September "asthma epidemic" is seen in many countries. Figure 2 stratifies asthma admissions to hospitals in Scotland by month, and September has the highest proportion of admissions $(12.2 \%)$ with November following closely behind (11.7\%), while July (4.7\%) and January (6.6\%) have the fewest asthma admissions. Other noninfective environmental factors linked to asthma attacks in younger children include exposures to secondhand smoke, outdoor air pollution, and unflued indoor heaters. ${ }^{24} \mathrm{~A}$ systematic review found that there was an absence of evidence (as opposed to evidence of absence) for associations between asthma attacks in children and other exposures including mold, traffic fumes, and inhaled and ingested allergens. ${ }^{24}$ Exposure to nonsteroidal anti-inflammatory drugs is associated with asthma attacks in adults but there is a good level of evidence that ibuprofen 


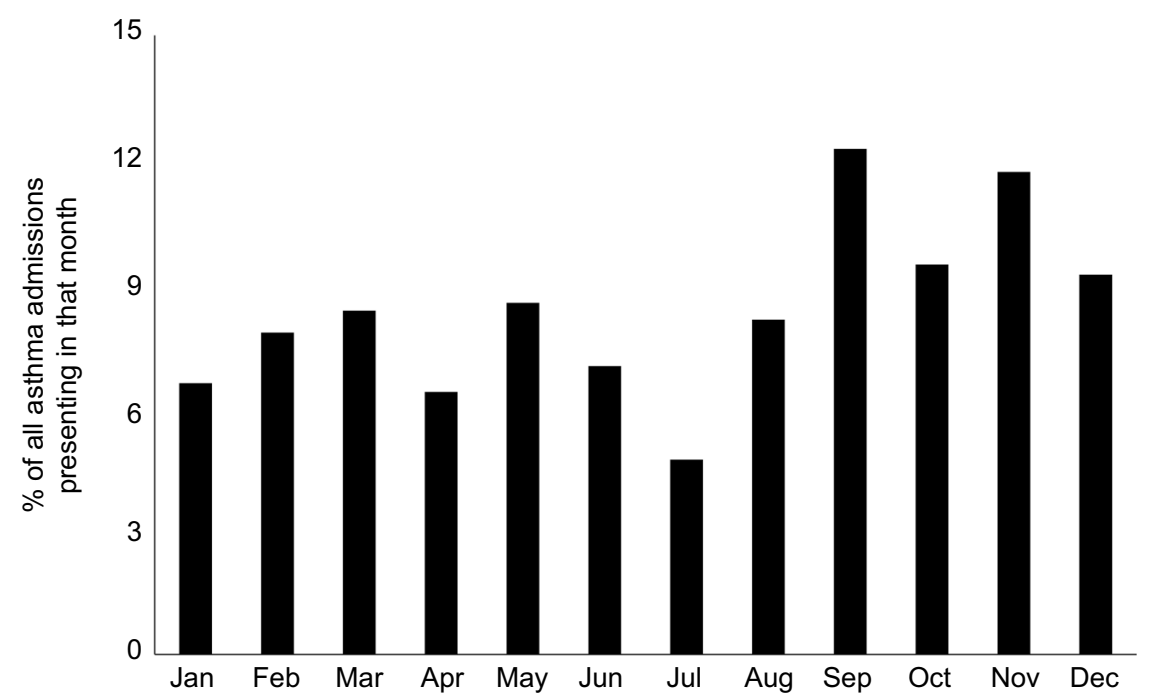

Figure $2 \mathrm{~A}$ bar chart showing the percentage of asthma admissions by calendar month of individuals aged under 16 years to hospitals in Scotland between 2000 and 2013.

Table I Summary of factors associated with increased risk of asthma attacks in children with diagnosed asthma

\begin{tabular}{lll}
\hline $\begin{array}{l}\text { Demographic } \\
\text { factors }\end{array}$ & $\begin{array}{l}\text { Environmental } \\
\text { factors }\end{array}$ & Asthma factors \\
\hline Male sex & Rhinovirus and other & Severity \\
Younger age & respiratory viruses & Asthma understanding \\
& Secondhand smoke & Holding an asthma plan \\
& (and active smoking) & Inappropriate treatment \\
& Ambient air pollution & Treatment adherence \\
& Unflued heating & \\
\hline
\end{tabular}

Note: Factors associated with attacks in children not previously diagnosed with asthma are not known, but are likely to be similar to those listed in the table.

is safe in most children with asthma, ${ }^{26}$ although ibuprofensensitive asthma does occur in less than $1 \%$ of children with asthma; ${ }^{27}$ so the question still has to be asked "has your child had ibuprofen before and if so were they OK?" One study has looked at multiple environmental exposures associated with asthma attacks and concluded the allergen exposure was not associated with asthma attacks but did observe an interaction where the highest risk of hospitalization was among those with an exposure to virus and who were skin prick positive. ${ }^{28}$ The study by Murray et $\mathrm{al}^{28}$ suggests that the severity of an asthma attack may be due to the host response to an otherwise innocuous respiratory virus infection.

In addition to many environmental factors, there are a number of treatment factors that are associated with asthma attacks. A study published in 1999 examined 250 consecutive acute asthma admissions in children with previously diagnosed asthma and identified that 95\% had not used their asthma management plan, 50\% had a low level of asthma knowledge, 30\% were not on appropriate treatment, and $20 \%$ were poorly adherent to treatment ${ }^{6}$ (Table 1 ). An earlier study had identified a clear link between poor adherence and risk of asthma attacks in children. ${ }^{29}$ Almost 20 years later, the situation remains mostly unchanged in the UK, and the 2015 NRAD recommends the following in order to prevent bad asthma outcomes in children: every patient should have a personal action plan; education of both children, parents, and teachers; and improved adherence to treatment. $^{30}$

\section{Interventions that might reduce asthma attacks in children}

So far, this article has described the large burden of asthma attacks in children and has identified a number of potentially modifiable environmental and treatment factors that might reduce this burden. So, how can this be implemented into routine primary care practice in order to reduce an individual's risk of an asthma attack tomorrow, in 5 and in 10 years' time?

\section{Tomorrow}

The management of asthma is well described in many national guidelines such as the British Thoracic Society/ Scottish Intercollegiate Guidelines Network "Asthma Guideline". ${ }^{31}$ Many of the recommendations in the NRAD report ${ }^{30}$ are already in place in most primary care settings where there is a semistructured patient-centered consultation between patient and health care professional during which asthma control, education, and treatment adherence are discussed and a written action plan (WAP) is agreed upon. It is beyond the remit of this review to go into all details of asthma management; however, a few topical aspects are mentioned here, which are as follows: 


\section{Written action plans}

While a WAP is widely accepted as good practice in asthma education and self-management, the evidence base for this practice is thin, and this most likely reflects the difficulty in teasing out the effect of a WAP from the complex intervention that is the clinician-patient consultation. A now rather old Cochrane review (published in 2006) concluded that symptom-based WAPs were more effective in reducing exacerbations compared to peak flow-based WAP; ${ }^{32}$ a trial published in 2004 demonstrated that peak flow monitoring was not effective in preventing attacks in children ${ }^{33}$ and peak flow monitoring is not routinely recommended for pediatric asthma management. A recent randomized control trial undertaken in "subspecialty" practice in the US recruited adults and children and found no benefit of a WAP over no written instructions ${ }^{34}$ it seems that the benefit from a WAP arises from more than simply having a handheld document to refer to when symptoms increase.

\section{Adherence}

Adherence to treatment is an important part of asthma education and self-management, and a very recently published systematic review has demonstrated that poor adherence is associated with $\sim 40 \%$ increased risk of asthma attacks in children. ${ }^{35}$

\section{The child's environment}

Children who are exposed to secondhand smoke are at increased risk of asthma attacks, ${ }^{24}$ and parents should be encouraged to create a smoke-free home and ultimately to quit smoking; childhood admissions with asthma attacks have reduced since smoke-free legislation was introduced. Knowing that September is the peak time for asthma attacks, educational interventions in primary care that promote adherence and explain what to do in the event of an attack may prove useful during the summer. One trial demonstrated how stepping up treatment during September and October was associated with a $78 \%$ reduction in unscheduled health care appointments when compared to placebo; ten children would require additional treatment to prevent one attack. ${ }^{36}$ At the time of writing, there are no recommendations that treatment should be stepped up during September.

\section{Five years' time: automated alerts}

There is proof of concept in adult populations that primary care records can be used to alert primary care staff to patients who are at high risk of asthma attacks, ${ }^{37}$ although differences in lifestyle (eg, smoking) and comorbidities (eg, COPD or diagnosed depression) mean that this needs to be replicated in children. "Avoiding hospital admissions", a document by the King' Fund, described an educational intervention to parent and child in accident and ED might reduce a child's risk of future admissions by $20 \% ;{ }^{38}$ might this approach work in the primary care setting? The use of modern technologies in improving asthma outcomes is still to be fully understood; however, a study in young people found no evidence for improved asthma control by daily clinical advice based on symptoms, treatment use, and peak flow measurements. ${ }^{39}$ Very little is understood regarding what data collected in primary care might be used to predict asthma attacks in children but once identified, this information could lead to the development of automated "alerts" on practice systems to identify patients at risk of future asthma attacks. The analysis of data from two large UK primary care databases to determine what factors predicted asthma attacks in children considered clinical records plus physiological parameters (ie, blood eosinophilia and peak flow). Among the 3,776 children with asthma, eosinophilia but not peak flow was weakly predictive of $\geq 1$ future attacks (odds ratio [OR] 1.6), treatment step was also weakly predictive (OR for attack relative to step 0 was 1.6 for step 3 and 2.0 for steps 4 and 5), and past OCS treatment was moderately predictive (OR compared to no OCS in the previous year was 4.3 with one course of OCS and 6.6 with two courses). ${ }^{40}$ Only $29 \%$ of children with poor asthma control went on to have an asthma attack in the following year, whereas $8 \%$ of children with well-controlled asthma had an attack. ${ }^{40}$ Although eosinophilia and reduced peak flow do not appear to be useful predictors of an attack, treatment guided by exhaled nitric oxide has been shown to reduce a child's risk of an asthma attack by $30 \%{ }^{41} \mathrm{~A}$ past history of attack appears to be a good index of future attacks; further work is now required to derive algorithms that can reduce a child's risk of attack, and exhaled nitric oxide testing might be a useful adjunct.

\section{Ten years' time: stratified treatment}

Within a population of children with asthma, there will be heterogeneity in the natural history, severity, response to treatment, and pattern of symptoms, and so it makes sense to stratify or individualize treatment. One method to stratify treatment is to use genotype to identify which treatment the individual is genetically predisposed to best respond to (or at least risk from being harmed by). One example is likely to be the Gly to Arg single-nucleotide polymorphism of the gene coding for the beta 2 adrenoceptor (rs1042713) where children carrying one or two Arg alleles are at increased risk 
of asthma attacks if treated with inhaled corticosteroids plus long-acting beta agonists compared to children carrying no Arg alleles. ${ }^{14}$ The potential for biomarkers to guide treatment or to predict an attack is still to be realized, but there is proof of concept that an increase in exhaled nitric oxide ${ }^{42}$ or a fall in peak flow ${ }^{43}$ may indicate that an attack may be developing and this opens the door for early interventions. Ultimately, asthma is the result of interactions between genetic and environmental factors. Modification of the child's environment might reduce the risk of attacks but complex interventions, which change several exposures, are more likely to be effective. ${ }^{44}$ Although single interventions such as flued heating are effective, ${ }^{45}$ interventions aimed at modifying exposure to single allergens are ineffective. ${ }^{24,46}$

\section{Conclusion}

Childhood asthma attacks are very common, often predictable, and amenable to prevention. The relationship between patient and health care professional plays a central role in preventing attacks. In future, technologies will add to the foundation stone of asthma management by personalizing treatment and flagging up children at risk of asthma attacks. Asthma prevention is likely to happen before asthma can be cured, and so health care professionals will be preventing and managing asthma attacks for another generation or two.

\section{Disclosure}

The author reports no conflicts of interest in this work.

\section{References}

1. World Health Organization. 10 Facts on Asthma. World Health Organization; 2011. Available from: http://www.who.int/features/factfiles/ asthma/en/. Accessed June 6, 2016.

2. Asher MI, Montefort S, Bjorksten B, et al. Worldwide time trends in the prevalence of symptoms of asthma, allergic rhinoconjunctivitis, and eczema in childhood: ISAAC Phases One and Three repeat multicountry cross-sectional surveys. Lancet. 2006;368(9537):733-743.

3. Kelly WJ, Hudson I, Phelan PD, Pain MC, Olinsky A. Childhood asthma in adult life: a further study at 28 years of age. Br Med J (Clin Res Ed). 1987;294(6579):1059-1062.

4. Tagiyeva N, Devereux G, Fielding S, Turner S, Douglas G. Outcomes of childhood asthma and wheezy bronchitis. A 50-year cohort study. Am J Respir Crit Care Med. 2016;193(1):23-30.

5. Holgate S, Bisgaard H, Bjermer L, et al. The Brussels Declaration: the need for change in asthma management. Eur Respir J. 2008;32(6):1433-1442.

6. Ordonez GA, Phelan PD, Olinsky A, Robertson CF. Preventable factors in hospital admissions for asthma. Arch Dis Child. 1998;78(2):143-147.

7. Reddel HK, Taylor DR, Bateman ED, et al. An official American Thoracic Society/European Respiratory Society statement: asthma control and exacerbations: standardizing endpoints for clinical asthma trials and clinical practice. Am J Respir Crit Care Med. 2009;180(1): 59-99.

8. Schatz M, Sorkness CA, Li JT, et al. Asthma control test: reliability, validity, and responsiveness in patients not previously followed by asthma specialists. J Allergy Clin Immunol. 2006;117(3):549-556.
9. Turner S, Thomas M, von Ziegenweidt J, Price D. Prescribing trends in asthma: a longitudinal observational study. Arch Dis Child. 2009;94(1):16-22.

10. Turner SW, Richardson K, Burden A, Thomas M, Murray C, Price D. Initial step-up treatment changes in asthmatic children already prescribed inhaled corticosteroids: a historical cohort study. NPJ Prim Care Respir Med. 2015;25:15041.

11. Engelkes M. Asthma Epidemiology, Treatment and Exacerbations [dissertation]. 2016.

12. Belhassen M, de Pouvourville G, Laforest L, et al. Effectiveness of montelukast on asthma control in infants: methodology of a French claims data study. BMC Pulm Med. 2015;15: 51.

13. European Respiratory Society. The White Book: Childhood Asthma. European Respiratory Society; 2013. Available from: http://www. erswhitebook.org/chapters/childhood-asthma/. Accessed July 15, 2016.

14. Turner S, Francis B, Vijverberg S, et al. Childhood asthma exacerbations and the Arg 16 32-receptor polymorphism: a meta-analysis stratified by treatment. J Allergy Clin Immunol. 2016;138(1):107-113.

15. Center for Disease Control and Prevention. Asthma Facts. 2013. Available from: http://www.cdc.gov/asthma/pdfs/asthma_facts_program_grantees.pdf. Accessed July 13, 2016.

16. Barnish MS, Tagiyeva N, Devereux G, Aucott L, Turner S. Diverging prevalences and different risk factors for childhood asthma and eczema: a cross-sectional study. Brit Med J Open. 2015;5(6):e008446.

17. Stevens MW, Gorelick MH. Short-term outcomes after acute treatment of pediatric asthma. Pediatrics. 2001;107(6):1357-1362.

18. Royal College of Physicians. Why asthma still kills? 2015.

19. Wang LY, Zhong Y, Wheeler L. Direct and indirect costs of asthma in school-age children. Prev Chronic Dis. 2005;2(1):A11.

20. Lenney W. The burden of pediatric asthma. Pediatr Pulmonol Suppl. 1997;15:13-16.

21. Bahadori K, Doyle-Waters MM, Marra C, et al. Economic burden of asthma: a systematic review. BMC Pulm Med. 2009;9:24.

22. Jackson DJ, Johnston SL. The role of viruses in acute exacerbations of asthma. J Allergy Clin Immunol. 2010;125(6):1178-1187.

23. Lee SL, Chiu SS, Malik PJ, Chan KH, Wong HS, Lau YL. Is respiratory viral infection really an important trigger of asthma exacerbations in children? Eur J Pediatr. 2011;170(10):1317-1324.

24. Dick S, Doust E, Cowie H, Ayres JG, Turner S. Associations between environmental exposures and asthma control and exacerbations in young children: a systematic review. Brit Med J Open. 2014;4(2): e003827.

25. Sears MR, Johnston NW. Understanding the September asthma epidemic. J Allergy Clin Immunol. 2007;120(3):526-529.

26. Kader A, Hildebrandt T, Powell C. How safe is ibuprofen in febrile asthmatic children? Arch Dis Child. 2004;89(9):885-886.

27. Debley JS, Carter ER, Gibson RL, Rosenfeld M, Redding GJ. The prevalence of ibuprofen-sensitive asthma in children: a randomized controlled bronchoprovocation challenge study. J Pediatr. 2005;147(2):233-238.

28. Murray CS, Poletti G, Kebadze T, et al. Study of modifiable risk factors for asthma exacerbations: virus infection and allergen exposure increase the risk of asthma hospital admissions in children. Thorax. 2006;61(5):376-382.

29. Milgrom H, Bender B, Ackerson L, Bowry P, Smith B, Rand C. Noncompliance and treatment failure in children with asthma. J Allergy Clin Immunol. 1996;98(6 Pt 1):1051-1057.

30. Royal College of Physicians. National Review of Asthma Deaths. Available from: https://www.rcplondon.ac.uk/projects/national-reviewasthma-deaths. Accessed June 11, 2015.

31. British Thoracic Society, Scottish Intercollegiate Guidelines Network. British Guideline on the Management of Asthma: A National Clinical Guideline (SIGN 141) [updated October 2014]. Available from: http:// www.sign.ac.uk/pdf/SIGN141.pdf. Accessed July 18, 2016.

32. Bhogal S, Zemek R, Ducharme FM. Written action plans for asthma in children. Cochrane Database Syst Rev. 2006;19(3):CD005306.

33. Wensley D, Silverman M. Peak flow monitoring for guided selfmanagement in childhood asthma: a randomized controlled trial. Am J Respir Crit Care Med. 2004;170(6):606-612. 
34. Sheares BJ, Mellins RB, Dimango E, et al. Do patients of subspecialist physicians benefit from written asthma action plans? Am J Respir Crit Care Med. 2015;191(12):1374-1383.

35. Engelkes M, Janssens HM, de Jongste JC, Sturkenboom MC, Verhamme KM. Medication adherence and the risk of severe asthma exacerbations: a systematic review. Eur Respir J. 2015;45(2):396-407.

36. Johnston NW, Mandhane PJ, Dai J, et al. Attenuation of the September epidemic of asthma exacerbations in children: a randomized, controlled trial of montelukast added to usual therapy. Pediatrics. 2007;120(3) e702-e712.

37. Smith JR, Noble MJ, Musgrave S, et al. The at-risk registers in severe asthma (ARRISA) study: a cluster-randomised controlled trial examining effectiveness and costs in primary care. Thorax. 2012;67(12):1052-1060.

38. Purdy S. Avoiding Hospital Admissions - What Does the Research Evidence Say? 2010. Available from: http://www.kingsfund.org.uk/sites/ files/kf/Avoiding-Hospital-Admissions-Sarah-Purdy-December2010. pdf. Accessed May 30, 2016.

39. Ryan D, Price D, Musgrave SD, et al. Clinical and cost effectiveness of mobile phone supported self monitoring of asthma: multicentre randomised controlled trial. BMJ. 2012;344:e1756.

40. Turner S, Burden A, Thomas M, Murray C, Price D. Predicting asthma exacerbations in children - a real life observational study. Eur Respir J. 2015;46(Suppl 59): PA4511.
41. Turner S. Exhaled nitric oxide and the management of childhood asthma - yet another promising biomarker "has been" or a misunderstood gem. Paediatr Respir Rev. 2015;16(2):88-96.

42. Pijnenburg MW, Hofhuis W, Hop WC, De Jongste JC. Exhaled nitric oxide predicts asthma relapse in children with clinical asthma remission. Thorax. 2005;60(3):215-218.

43. Frey U, Brodbeck T, Majumdar A, et al. Risk of severe asthma episodes predicted from fluctuation analysis of airway function. Nature. 2005;438(7068):667-670.

44. Morgan WJ, Crain EF, Gruchalla RS, et al. Results of a home-based environmental intervention among urban children with asthma. $\mathrm{N} \mathrm{Engl}$ J Med. 2004;351(11):1068-1080.

45. Howden-Chapman P, Pierse N, Nicholls S, et al. Effects of improved home heating on asthma in community dwelling children: randomised controlled trial. BMJ. 2008;337 a1411.

46. Glasgow NJ, Ponsonby A, Kemp A, et al. Feather bedding and childhood asthma associated with house dust mite sensitisation: a randomised controlled trial. Arch Dis Child. 2011;96(6):541-547.

47. Health and Social Science Information Centre. Hospital Episode Statistics. 2015. Available from: http://digital.nhs.uk/searchcatalogue?q=title$\% 3 \mathrm{~A} \% 22 \mathrm{Hospital}+$ Episode+Statistics $\% 2 \mathrm{C}+\mathrm{Admitted}+$ patient+care++ England $\% 22 \&$ area $=\&$ size $=10 \&$ sort $=$ Relevance. Accessed August 10 2016.
Pragmatic and Observational Research

\section{Publish your work in this journal}

Pragmatic and Observational Research is an international, peer-reviewed open access journal that publishes data from studies designed to reflect more closely medical interventions in real-world clinical practice compared with classical randomized controlled trials (RCTs). The manuscript management system is completely online and includes a very quick and fair peer-review

\section{Dovepress}

system. Visit http://www.dovepress.com/testimonials.php to read real quotes from published authors.

Submit your manuscript here: https://www.dovepress.com/pragmatic-and-observational-research-journal 